\title{
Igualdad y no discriminación de los inmigrantes en Colombia: análisis desde el derecho al trabajo
}

\author{
Equality and non-discrimination of immigrants in Colombia: analysis from the right
}

to work

\begin{abstract}
Angélica Armenta Ariza
Abogada. Especialista en Derecho administrativo. Especialista Derecho Constitucional. Magister en Derecho Administrativo. Docente investigadora del Colegio Jurídico y de Ciencias Sociales de la Institución Universitaria Colegios de Colombia, UNICOC. Red de Grupos y Centros de Investigación Jurídica y Socio jurídica. Proyecto "Diagnóstico regional de la migración en Colombia con enfoque de DDHH
\end{abstract} (2014 - 2018).

Fecha de recepción: Agosto de 2019 Fecha de aprobación: marzo de 2020

Para citar este artículo / To reference this article Igualdad y no discriminación de los inmigrantes en Colombia: análisis desde el derecho al trabajo. Inciso, 22(1) ; $130-143$.

DOI: http://dx.doi.org/10.18634/incj.22v.1i.1034

\section{Resumen}

Este artículo describe el marco internacional de derechos humanos de los inmigrantes en Colombia, se enfatiza en las normas que hacen parte del bloque de constitucionalidad, y que garantizan el derecho a la igualdad y el principio de no discriminación de esta población. Se plantea la tesis según la cual, de conformidad con las normas internacionales de derechos humanos, el Estado colombiano adquirió el compromiso internacional de respeto, garantía y protección de los derechos humanos de los inmigrantes en el territorio nacional, mediante la suscripción de tratados y/o convenios internacionales que reconocen el derecho a la igualdad y el principio de no discriminación; y posteriormente, se hace una relación de estos conceptos, la igualdad y el principio de no discriminación desde la óptica del derecho al trabajo; para concluir que la política migratoria colombiana en materia de derechos humanos, debe tener como sustento axiológico la garantía del derecho a la igualdad y el principio de no discriminación entre nacionales y extranjeros, salvo que se trate de distinciones acordes con el principio de razonabilidad. La metodología que se utilizó, es de tipo descriptivo, ya que se aborda y desarrollan desde un enfoque conceptual, las normas internacionales de derechos humanos que en materia migratoria hacen parte del bloque de constitucionalidad para el caso colombiano; por 
lo que, como se precisó, se aborda la misma desde un enfoque teórico descriptivo, precisando cuáles son las normas internacionales de protección de los derechos humanos de la población inmigrante y la obligaciones del Estado colombiano a partir del bloque de constitucionalidad.

Palabras clave: derechos civiles, derechos humanos, discriminación,inmigración, política pública.

\section{Abstract}

This article describes the international human rights framework of immigrants in Colombia, emphasizing on the norms that are part of the constitutionality block, and that guarantee the right to equality and the principle of non-discrimination of this population in the Colombian legal system; subsequently, a relation of these concepts (equality and the principle of nondiscrimination), is made from the perspective of the right to work, to propose the thesis according to which, in accordance with international human rights standards, the Colombian State acquired by subscription of international treaties and / or conventions, the international commitment to respect, guarantee and protection of the human rights of immigrants in the national territory. Finally, it is concluded that Colombian migration policy in the field of human rights must have as axiological support the maximum of the right to equality and the principle of non-discrimination between nationals and foreigners, unless they are distinctions according to the principle of reasonableness. The methodology that was used is descriptive, because it develops from a conceptual approach, international human rights norms in the field of immigrant rights, which are part of the constitutionality block in Colombia. Therefore, as stated above, it is approached from a descriptive theoretical approach, specifying what are the international norms for the protection of the human rights of the immigrant population and the obligations of the Colombian State from the constitutionality block.

Key words: immigration, human rights, discrimination, public policy, constitution, civil rights.

\section{Introducción}

El texto aborda el derecho a la igualdad y el principio de no discriminación de derechos humanos de los inmigrantes en Colombia, tomando como eje central el derecho a la igualdad de la población migrante en relación con el derecho al trabajo. La investigación hace parte de proyecto "Diagnóstico regional de la migración en Colombia con enfoque de DDHH (2014 - 2018)" que desarrolló el Colegio Jurídico y de Ciencias Sociales de la Institución Universitaria Colegios de Colombia-UNICOC- con la Universidad del Rosario, entre otras universidades, dentro del marco de la Red socio jurídica, y dentro del enfoque institucional, se presenta el artículo titulado: "El derecho a la igualdad y el principio de no discriminación de los derechos humanos de los inmigrantes en Colombia: análisis en relación con el derecho al trabajo".

El problema planteado consiste en determinar:¿Cuáles son las normas del bloque de constitucionalidad, que garantizan y protegen el derecho a la igualdad y el principio de no discriminación de la población inmigrante en Colombia? Determinado lo anterior, se hace un análisis de estos dos postulados de derechos humanos, esto es, igualdad y prohibición de discriminación, en relación con el derecho al trabajo, teniendo en cuenta que el Estado colombiano ha suscrito diversos tratados y/o convenios internacionales, en los cuales ha adquirido el compromiso internacional de respetar, proteger y garantizar en condiciones de 
igualdad con los nacionales colombianos, los derechos humanos de la población inmigrante, lo que involucra a su vez la garantía no solo de protección en condiciones de igualad, sino a su vez el principio de no discriminación en materia de derechos humanos. Para finalmente, señalarlas obligaciones que surgen a partir de la suscripción de los convenios internacionales de derechos humanos, para el Estado colombiano en materia de la política pública migratoria, la cual debe tener como elemento axiológico, el derecho a la igualdad y el principio de no discriminación por razón del origen nacional (categoría sospechosa de discriminación), tal y como lo determina el artículo 2 y 13 de la Constitución Política y las normas del bloque de constitucionalidad.

El texto se presenta en tres secciones, así: en la primera, se revisan las normas internacionales de derechos humanos de la población inmigrante, las cuales para el caso colombiano, hacen parte del bloque de constitucionalidad; en la segunda, se aborda el derecho a la igualdad y el principio de no discriminación en materia de derechos humanos de la población inmigrante, se analiza la garantía de este derecho humano: la igualdad, en relación con el derecho al trabajo; para finalmente, como punto central del documento, señalar las obligaciones de acción que surgen para Colombia en materia de política pública, a partir del bloque de constitucionalidad, política que debe tener como eje central y sustento ontológico, el derecho a la igualdad y el principio de no discriminación por razón del origen nacional, lo cual como lo ha mencionado la Corte Constitucional, se encuentra dentro de las categorías sospechosas de discriminación (categoría sospechosa de discriminación).

\section{Materiales y métodos}

La metodología utilizada en la investigación es de tipo descriptivo, por cuanto, se abordan y desarrollan desde un enfoque conceptual las normas internacionales de derechos humanos que en materia migratoria hacen parte del bloque de constitucionalidad para el caso colombiano, que lo comprometen como Estado partea garantizar los derechos humanos de esta población, en condiciones de igualdad con los nacionales, bajo el amparo del principio de no discriminación en razón del origen nacional.

Es en este sentido que la misma se aborda desde un enfoque teórico (descriptivo), precisando cuáles son las normas internacionales de protección de los derechos humanos de los inmigrantes, su vinculación y obligación para la Estado colombiano como normas que integran el bloque de constitucionalidad, y su respeto y garantía sin ningún tipo de discriminación con fundamento en las categorías sospechosas de discriminación.

\section{El bloque de constitucionalidad de los inmigrantes en Colombia}

Esta sección presenta las normas internacionales de derechos humanos de la población inmigrante en Colombia, y que hacen parte del bloque de constitucionalidad. Inicialmente, se encuentra la Declaración Universal de los Derechos Humanos (1948), primer documento internacional que consagra los derechos fundamentales de todas las personas sin distingo de ninguna naturaleza, así mismo, define el compromiso de la comunidad internacional en la protección de estos derechos. Esta declaración, toma como eje de inspiración "el reconocimiento de la dignidad intrínseca y de los derechos iguales e inalienables de todos los miembros de la familia humana" (Naciones Unidas, 1948), en ese sentido, el artículo 2 señala:

Toda persona tiene todos los derechos y libertades proclamados en esta Declaración, sin distinción alguna de raza, color, sexo, idioma, religión, opinión política o de cualquier otra índole, origen nacional o social, posición económica, nacimiento o cualquier otra condición. Además, no se hará distinción alguna fundada en la condición política, jurídica o internacional del país o territorio de cuya jurisdicción dependa una persona, tanto si se trata de un país independiente, como de un territorio bajo administración fiduciaria, no autónomo o sometido a cualquier otra limitación de soberanía.(Declaracion de Derechos Humanos, art.2, 1948). (Negrillas fuera del texto original). 
El artículo 7 del mismo documento, señala: “Todos son iguales ante la ley y tienen, sin distinción, derecho a igual protección de la ley. Todos tienen derecho a igual protección contra toda discriminación que infrinja esta Declaración y contra toda provocación a tal discriminación"(Declaracion Universal de Derechos Humanos, art.7, 1948).

A su vez, el artículo 2 numeral 1 del Pacto Internacional de Derechos Civiles y Políticos, señala la obligación y compromiso internacional de los Estados partes de respetar y garantizar a todos los individuos que se encuentren en su territorio, los derechos reconocidos en él mismo, e impone que tal obligación de respeto y protección debe hacerse sin ningún tipo de discriminación por razón de raza, color, sexo, idioma, religión, opinión política o de otra índole, origen nacional o social, posición económica, nacimiento o cualquier otra condición social(Pacto Internacional de Derechos Civiles y Políticos, artículo2 numeral1, 1966). (Negrillas fuera del texto original).

Adicionalmente, el artículo 26 del mencionado pacto, consagra el derecho fundamental a la igualdad, y dispone, que este debe ejercerse sin ningún tipo de discriminación, es así como, se expresa en el citado artículo:

Todas las personas son iguales ante la ley y tienen derecho sin discriminación a igual protección de la ley. A este respecto, la ley prohibirá toda discriminación y garantizará a todas las personas protección igual y efectiva contra cualquier discriminación por motivos de raza, color, sexo, idioma, religión, opiniones políticas o de cualquier índole, origen nacional o social, posición económica, nacimiento o cualquier otra condición social(Naciones Unidas, 1966)(Cursivas y negrilla fuera del texto original).

Posteriormente, se adoptó en San José Costa Rica el 22 de noviembre de 1969 la Convención Americana de Derechos Humanos(Convención Americana Sobre Derechos Humanos, 1969), la cual entró en vigor el 18 de julio de 1978; instrumento internacional que desde el preámbulo reconoce que los derechos esenciales del hombre, no nacen del hecho de ser nacional de determinado Estado, sino que tienen como fundamento los atributos de la persona humana(Convencion Americana Sobre Derechos Humanos, preambulo, 1969); de esta manera, el reconocimiento de los derechos esenciales de la persona humana son el fundamento ontológico que vincula a los estados de América para unirse en un compromiso de nivel internacional, en la protección de estos derechos, protección que opera de manera convencional o complementaria con la legislación interna, y en éste derrotero en materia de protección convencional, se encuentra el numeral 1 del artículo 1, el cual está en sintonía con el preámbulo de la misma norma, y dispone:

Los Estados Partes en esta Convención se comprometen a respetar los derechos y libertades reconocidos en ella y a garantizar su libre y pleno ejercicio a toda persona que esté sujeta a su jurisdicción, sin discriminación alguna por motivos de raza, color, sexo, idioma, religión, opiniones políticas o de cualquier otra índole, origen nacional o social, posición económica, nacimiento o cualquier otra condición social(Convención Americana Sobre Derechos Humanos, numeral 1 artículo1, 1969).

Así mismo, el artículo 24 de la referida convención, consagra el derecho de todas las personas ante la ley, garantía de la cual emerge la consecuencia de prohibición de discriminación (Convencion Americana Sobre Derechos Humanos, artículo 24, 1969).

Otra norma de nivel internacional que hace parte del bloque de constitucionalidad para el caso colombiano, son los convenios de la OIT, de conformidad con lo dispuesto en el artículo 53 inciso 4 de la Constitución Política, que señala: "Los convenios internacionales del trabajo debidamente ratificados, hacen parte de la legislación interna"(Constitución Política de Colombia, articulo 53, 1991); en tal sentido, el trabajo 
tiene doble garantía de protección, por un lado en el plano nacional, como derecho fundamental en el artículo 25 de la Constitución Política, esto es, el derecho al trabajo como derecho humano fundamental, y en ese sentido, hace parte del bloque de constitucionalidad; y a su vez, por otro lado, como garantía de refuerzo en el plano internacional, se encuentran los convenios de la OIT que estén debidamente ratificados por Colombia, los cuales entran a hacer parte no solo de la legislación interna, sino del bloque de constitucionalidad en sentido estricto en materia laboral, así lo dispuso la Corte Constitucional en la sentencia C 067 de 2003, a la altura de la consideración jurídica No. 3 literal b (Corte Constitucional , 2003, p. 8).

Siguiendo esta misma línea, dentro del marco de los convenios de la Organización Internacional del Trabajo (OIT) se encuentra el Convenio 111, adoptado en Ginebra el 25 de junio de 1958, el cual se refiere a la discriminación en materia de empleo y ocupación. Es preciso señalar que este documento fue ratificado por Colombia el 4 de marzo de 1969, y actualmente se encuentra en vigor (C111 - Convenio Sobre la Discriminación (empleo y ocupación), 1958). La relevancia de este convenio para el escrito que nos ocupa, consiste en que el mismo se encuentra inspirado en los principios pro homine, dignidad humana, igualdad y no discriminación, y dispone que los mencionados principios se deben aplicar a la protección de derechos en materia laboral, sin que exista ningún tipo de trato desigual por razones de nacionalidad o estatus migratorio. Teniendo en cuenta lo anterior, el Convenio 111 señala en el numeral 1 del artículo 1:

las conductas que se enmarcan como actos discriminatorios, dentro de las cuales señala actos como (...) (a) cualquier distinción, exclusión o preferencia basada en motivos de raza, color, sexo, religión, opinión política, ascendencia nacional u origen social que tenga por efecto anular o alterar la igualdad de oportunidades o de trato en el empleo y la ocupación(...)"(C111- Convenio Sobre la Discriminación (empleo y ocupación), artículo 1, 1958) (Negrillas fuera del texto original).

Dentro de otros instrumentos internacionales que regulan el derecho a la igualdad y el principio de no discriminación en materia laboral de la población inmigrante en Colombia, se encuentran La Convención internacional sobre la protección de los derechos de todos los trabajadores migratorios y de sus familiares (Naciones Unidas, 1990), adoptada por la Asamblea General de las Naciones Unidas mediante Resolución 45/158 del 18 de diciembre de 1990, la cual señala en el literal numeral 1 del artículo 25:

“1. Los trabajadores migratorios gozarán de un trato que no sea menos favorable que el que reciben los nacionales del Estado de empleo en lo tocante a remuneración y de:

a) Otras condiciones de trabajo, es decir, horas extraordinarias, horario de trabajo, descanso semanal, vacaciones pagadas, seguridad, salud, fin de la relación de empleo y cualesquiera otras condiciones de trabajo que, conforme a la legislación y la práctica nacionales, estén comprendidas en este término;

b) Otras condiciones de empleo, es decir, edad mínima de empleo, restricción del trabajo a domicilio y cualesquiera otros asuntos que, conforme a la legislación y la práctica nacionales, se consideren condiciones de empleo."

A su vez, la citada disposición, señala en el numeral 3, la obligación por activa de los estados, de no implementar o establecer ningún tipo de reglamentación local que contenga distinciones y/o menoscabos en materia laboral, que tengan como base la situación migratoria, al señalar que

“3. Los Estados Partes adoptarán todas las medidas adecuadas para asegurar que los trabajadores migratorios no sean privados de ninguno de los derechos derivados de este principio a causa de irregularidades en su permanencia o empleo. En particular, los empleadores no quedarán exentos de ninguna obligación jurídica ni contractual, ni sus obligaciones se verán limitadas en forma alguna a causa 
de cualquiera de esas irregularidades"(Convención Internacional sobre la Protección de los Derechos de Todos los Trabajadores Migratorios y de sus Familiares, artículo 25 numeral 1 , 1990)(Negrillas y cursiva fuera del texto original).

A su vez, el artículo 26 de la misma norma ampara los derechos de los trabajadores migrantes, así como los de sus familiares, reconociéndoles derechos tales como, el de participar en reuniones y actividades sindicales, el derecho a afiliarse de manera libre a cualquier sindicato, solicitar ayuda y asistencia de cualquier sindicato; y concluye que el ejercicio de estos derechos solo puede estar sujeto a restricciones necesarias que sean propias de una sociedad democrática.(Naciones Unidas, 1990).

1. La Opinión Consultiva OC-18/03 del 17 de septiembre de 2003 de la Corte Interamericana de Derechos Humanos, sobre la condición jurídica y derechos de los migrantes indocumentados, (Corte Interamericana de Derechos Humanos, 2003),desarrolla las obligaciones de los estados en relación con los trabajadores migrantes, y señala dentro del catálogo de obligaciones, las siguientes:

(...) a). Obligación de respetar y garantizar los derechos humanos y carácter fundamental del principio de igualdad y no discriminación (preguntas no. 2.1 y 4);

b) Aplicación del principio de igualdad y no discriminación a los migrantes (pregunta no. 2.1);

c) Derechos de los trabajadores migrantes indocumentados (preguntas no. 2.2 y 1); y

d) Obligaciones estatales en la determinación de las políticas migratorias a la luz de los instrumentos internacionales de protección de los derechos humanos (pregunta no. 3). (...) (La Opinión Consultiva OC-18/03 Condición Jurídica y Derechos de los Migrantes Indocumentados, 2003, p. 96).

Al referirse a la obligación dispuesta en el literal a, esto es, referida al compromiso de respeto y garantía de los derechos humanos, la Corte señaló en la mencionada opinión, que estos derechos, deben ser respetados y garantizados por los Estados, ya que es incuestionable el hecho de que toda persona tiene atributos inherentes a su dignidad humana, los cuales le son inviolables por el solo hecho de ser persona, lo que la hace titular innegable de derechos fundamentales que no sele pueden desconocer y que, en consecuencia, son superiores al poder del mismo Estado, sea cual sea su tipo de organización política. (Corte Interamericana de Derechos Humanos, 2003).

2. Recomendación No. 151 de la OIT sobre los Trabajadores Migrantes(Organización Internacional del Trabajo, 1975).

Como se muestra en esta sección, existe un amplio número de instrumentos internacionales, que protegen los derechos humanos de la población inmigrante, los cuales hacen parte del bloque de constitucionalidad en Colombia, ya que ingresan al sistema mayor en virtud de las remisiones normativas que hacen los artículos 53 inciso 4, sobre los convenios de la OIT; 93, referido a los tratados de derechos humanos cuya garantía y protección no se pueden limitar ni suspender durante la vigencia de los estados de excepción; y, el artículo 94, que se refiere a la cláusulapro hominede derechos innominados superior (Asamblea Constituyente de Colombia, 1991).

Por lo anterior, como se explicó durante el desarrollo de la primera sección, no se pretende bajo ninguna premisa equiparar la condición de nacional con la de extranjero, en este caso, con la de migrantes, dado que se entiende que son conceptos categóricos diferentes, así lo establece la Constitución Política de 1991 en el artículo 100; sin embargo, la misma norma dispone, tal y como lo señaló la Corte Constitucional en la sentencia T 210 de 2018, que pese a esta diferencia de categorías jurídicas, existe el mandato de 
igualdad entre ambas, con la posibilidad de hacer distinciones entre una u otra, dentro del marco de unos criterios objetivos y razonables, que no permitan generar discriminación, en ese sentido señaló la Corte en el citado fallo:

(...) Si bien existe un mandato de igualdad expreso entre extranjeros y nacionales en el artículo 100 constitucional, la Carta autoriza la posibilidad de desarrollar un tratamiento diferenciado en relación con los nacionales; y, en segundo lugar, que las diferenciaciones realizadas con fundamento en la nacionalidad, por basarse en un criterio sospechoso de discriminación, son inadmisibles salvo que existan suficientes razones que las justifiquen (...). (Sentencia T 210 de 2018).

Es decir, de conformidad con las normas constitucionales, a los extranjeros en Colombia se les deben garantizar los mismos derechos civiles que a los nacionales; en tal sentido, lo que permite la Constitución es la realización de distinciones razonables, tal y como ocurre con algunos derechos políticos, los cuales están reservados a los nacionales colombianos. Fue así como concretó la Corte Constitucional en la referida sentencia:

[...] Si bien pueden hacerse distinciones, es preciso recordar que la jurisprudencia de esta Corporación también ha sido muy clara al establecer que las diferenciaciones basadas en el origen nacional, en principio, son constitucionalmente problemáticas pues se basan en un criterio sospechoso de discriminación. En otras palabras, las restricciones de los derechos de los extranjeros son inadmisibles salvo que existan suficientes razones constitucionales que las justifiquen (...).(sentencia T 210 de 2018)

Tomando como referente lo anterior, lo que se pretende señalar, es que con la inclusión de estos instrumentos internacionales al bloque de constitucionalidad, Colombia adquirió el compromiso de protección, garantía y respetode los derechos humanos de todas las personas residentes en el territorio, sean nacionales o extranjeros, y en este último caso, sin consideración al origen nacional. En este sentido, las garantías en derechos humanos reconocidas a nivel internacional para todas las personas, no deben ser concedidas por los estados solo a sus nacionales, sino a todos los que habitan el territorio nacional, lo cual incluye a los inmigrantes (con independencia de su situación migratoria), tengan status migratorio, situación irregular, asilado o refugiado. De tal manera que, con independencia de la situación migratoria, sus derechos humanos no pueden ser restringidos bajo ninguna circunstancia, tal premisa se respalda con lo planteado por la Corte Constitucional en la sentencia T 210 de 2018, la cual, si bien se refiere al derecho fundamental a la salud de la población inmigrante en Colombia, la misma es pertinente, ya que en ella, la Corte Constitucional hace alusión a los dos derechos abordados en este documento: la igualdad y la no discriminación en materia de derechos humanos de la población inmigrante, en tal sentido, sostuvo la Corte que:

[...] De acuerdo con el derecho internacional, los Estados deben garantizar a todos los migrantes, incluidos aquellos que se encuentran en situación de irregularidad, no solo la atención de urgencias con perspectiva de derechos humanos, sino la atención en salud preventiva con un enérgico enfoque de salud pública. No obstante, de acuerdo con otros instrumentos de derecho internacional y a algunos desarrollos recientes de softlaw sobre el contenido mínimo esencial del derecho a la salud de los migrantes, se ha establecido con fundamento en el principio de no discriminación, que (i) el derecho a la salud debe comprender la atención integral en salud en condiciones de igualdad e ir mucho más allá de la urgencia. Por eso, de contar con estándares más bajos, (ii) pese a los limitados recursos disponibles, los Estados tienen la "obligación concreta y constante de avanzar lo más expedita y eficazmente posible hacia la plena realización del artículo 12" del Pacto de Derechos Económicos, Sociales y Culturales mediante la adopción de medidas; especialmente y con mayor rigurosidad, cuando dichos estándares atentan contra una obligación de naturaleza inmediata, como lo es la obligación de no discriminación en la prestación del servicio de salud (...) (T 210 de 2018). 


\section{Igualdad y no discriminación de los inmigrantes: análisis desde el derecho al trabajo}

Esta sección aborda el derecho a la igualdad en materia de derechos humanos de la población inmigrante, y cómo éste se concreta en relación con el derecho al trabajo; se aclara para efectos metodológicos de la sección, que la misma, no tiene como propósito realizar un abordaje del marco internacional que protege y garantiza el derecho al trabajo, sino como se mencionó, se pretende enfatizar 'las normas que garantizan el derecho a la igualdad en materia laboral de la población inmigrante, el cual debe garantizarse sin ningún tipo de discriminación, como lo ordena la normatividad internacional; entre las que se destacan, la Declaración Universal de Derechos Humanos, el Pacto Internacional de Derechos Civiles y Políticos, la Convención Americana de Derechos Humanos, la Convención Internacional sobre la protección de los derechos de todos los trabajadores migratorios y de sus familiares y el Convenio 111 de la Organización Internacional del Trabajo, entre otros instrumentos internaciones de protección de los derechos de los inmigrantes.

Los documentos internacionales citados, disponen que los derechos humanos de los inmigrantes deben ser respetados, garantizados y protegidos por la comunidad internacional, y para el caso puntual, por el estado receptor, en condiciones de igualdad en relación con los nacionales de dicho estado, prohibiendo de este modo, todo tipo de trato discriminatorio que genere desigualdades de facto en consideración al origen nacional, así lo reconocen, la Convención Americana de Derechos Humanos a partir del artículo 1 y los artículos 2 y 26 del Pacto Internacional de Derechos Civiles y Políticos, como el artículo 2 de la Declaración Universal de Derechos humanos, instrumentos internacionales, que consagran el principio de igualdad jurídica. En el mismo sentido, la Convención internacional sobre la protección de los derechos de todos los trabajadores migratorios y de sus familiares, adoptada por la Asamblea General mediante Resolución 45/158 del 18 de diciembre de 1990, dispone en el artículo 7:

[...] Los Estados Partes se comprometerán, de conformidad con los instrumentos internacionales sobre derechos humanos, a respetar y asegurar a todos los trabajadores migratorios y sus familiares que se hallen dentro de su territorio o sometidos a su jurisdicción los derechos previstos en la presente Convención, sin distinción alguna por motivos de sexo, raza, color, idioma, religión o convicción, opinión política o de otra índole, origen nacional, étnico o social, nacionalidad, edad, situación económica, patrimonio, estado civil, nacimiento o cualquier otra condición [...]. (Convención Internacional sobre la Protección de los Derechos de Todos los Trabajadores Migratorios y de sus Familiares, artículo 7, 1990)(Negrilla y cursiva fuera de texto). (Resolución 45/158 de 1990).

Teniendo en cuenta el derecho a la igualdad entre los hombres y el principio de no discriminación que de él emana, la Corte Interamericana de Derechos Humanos en la Opinión Consultiva OC-18/03 del 17 de septiembre de 2003, diferenció entre los conceptos de distinción y discriminación, precisando que el primero se emplea para lo admisible, por tratarse de aquello que resulta razonable, proporcional y objetivo, en tanto que, el término discriminación se utilizará para hacer referencia a lo inadmisible, por tratarse de hechos, circunstancias y/o situaciones que violan los derechos humanos (Corte Interamericana de Derechos Humanos, 2003). Al respecto, continua precisando la Corte, que el término discriminación hace referencia a toda exclusión, restricción o privilegio que no sea objetivo y razonable, que redunde en detrimento de los derechos humanos.(Opinión Consultiva OC-18/03 Condición Jurídica y Derechos de los Migrantes Indocumentados, Página 103, Numeral 84, 2003).

Siguiendo esta línea, la Corte sostiene que no se está frente a un acto de discriminación, cuando el tratamiento, medida o intervención estatal están orientadas legítimamente al amparo de las normas internacionales de derechos humanos; y que, por ende, no se trate de actos fruto de acciones o medidas caprichosas y/o arbitrarias que lesionan y agreden no solo la igualdad entre las personas, sino su dignidad. A su vez, el Comité de Derechos Humanos de las Naciones Unidas en la Observación General 18 del 10 
de noviembre de 1989, define la discriminación como:

[...] toda distinción, exclusión, restricción o preferencia que se basen en determinados motivos, como la raza, el color, el sexo, el idioma, la religión, la opinión política o de otra índole, el origen nacional o social, la posición económica, el nacimiento o cualquier otra condición social, y que tengan por objeto o por resultado anular o menoscabar el reconocimiento, goce o ejercicio, en condiciones de igualdad, de los derechos humanos y libertades fundamentales de todas las personas (...)(Observación General 18, Numeral 7, 1989) (Negrillas y cursiva fuera del texto original).

Ahora bien, siguiendo la línea del principio de no discriminación, y teniendo en cuenta que una de las mayores situaciones de discriminación a nivel mundial, son las que se generan en contra de la población inmigrante, es necesario mencionar las tres conferencias mundiales desarrolladas por las Naciones Unidas, las cuales han tenido como epicentro, la lucha contra el racismo y la discriminación en el mundo, puntualmente, la discriminación contra los inmigrantes en atención a su situación migratoria. Con base en los anteriores referentes internacionales, y en virtud del derecho a la igualdad y el principio de no discriminación, no deben existir medidas de orden legal, administrativo y/o judicial, que hagan acepciones ilegítimas en materia de derechos humanos, entre las personas por motivos de su nacionalidad, o en consideración a su situación migratoria, ya que de conformidad con el marco internacional, a toda las personas les deben ser respetados, protegidos y garantizados sus derechos humanos en cualquier Estado en el que resida, con independencia de su situación migratoria; y en tal sentido, para el caso colombiano, por regla general, cualquier medida que contenga o incorpore un trato diferente (discriminación), que afecte, perjudique o lesione los derechos humanos de la población inmigrante, viola los tratados y convenios internacionales suscritos por Colombia, los cuales, como ya se indicó en la sección anterior, hacen parte del bloque de constitucionalidad, generándose con ello una responsabilidad internacional por la violación de los derechos humanos de esta población.

Ahora bien, uno de los derechos humanos que mayor desigualdad genera para la población migrante, bien sea de facto o de iuris (leyes, decisiones judiciales), lo constituye el derecho al trabajo, en el que en atención a la nacionalidad o a la situación migratoria, se genera tratamiento diverso, que no solo puede resultar desfavorable en materia de derechos humanos, sino que a su vez, va en contravía de dos principios rectores del derecho internacional de los derechos humanos, como son la igualdad jurídica y la no discriminación, situación que es mucho más gravosa cuando se trata de trabajadores inmigrantes indocumentados. Lo anterior, sin dejar de lado que en el caso de estos, muchas veces reciben no solo un trato discriminatorio desde el marco legal o la institucionalidad, sino de la misma sociedad, cuando reciben tratamientos de rechazo, por ser considerados en algunas circunstancias una población que debe tener o a la que se le deben dar "menos derechos", por no ser nacionales del Estado receptor, tal y como lo ha sostenido la Corte Interamericana de derechos humanos en los múltiples conceptos en los cuales ha abordado la migración.

Teniendo en cuenta lo anterior, esto es, el derecho humano a la igualdad sin distingo al origen nacional, y el principio de no discriminación, se señala que, de conformidad con las normas internacionales de derechos humanos, todas las personas son iguales en derechos, y por tanto, merecen el mismo trato y protección de las autoridades públicas, las cuales están instituidas en el territorio nacional para proteger a todas las personas residentes en el territorio en su vida, honra, bienes y demás derechos y libertades, tal y como lo dispone el artículo 2 de la constitución política de 1991. En tal sentido, un trato diferente, en consideración a la situación migratoria, no solo atenta contra las normas internacionales de derechos humanos y los artículos 1 y 2 de la Constitución Política, sino que viola una norma del iuscogens como es el principio y derecho de la igualdad y el principio de no discriminación. 
A su vez, concretamente en materia laboral, tales disposiciones y/o situaciones, propician conductas y actos discriminatorios hacia los trabajadores inmigrantes, sobre todo si se trata de inmigrantes irregulares, por cuanto, permiten o abren la compuerta para que los empleadores no les respeten y garanticen los derechos laborales, prestacionales, la libre asociación y derechos sindicales entre otros; generando en dicha población, temor a acudir a reclamar sus derechos ante instancias judiciales por considerar que por su situación de irregularidad puedan ser deportados a su país de origen. Sobre este punto, ha sostenido la Corte Interamericana de Derechos Humanos, que en esos casos, se está no solo ante la vulneración del derecho a la igualdad jurídica de esta población, sino ante una desigualdad en materia sancionatoria entre el empleador y el trabajador inmigrante indocumentado, dado que en algunas ocasiones, los empleadores que contratan inmigrantes indocumentados no reciben ningún tipo de sanción del Estado, mientras que los inmigrantes, aunado al hecho de la desprotección de sus derechos laborales, terminan siendo deportados a su país de origen.

Es por la anterior desigualdad y desprotección en materia laboral de esta población, que la Corte Interamericana de Derechos Humanos en la Opinión Consultiva 18/2003, al referirse a la obligación de respeto y garantía de los derechos humanos, y el principio de igualdad y no discriminación, señaló que entre estos existe un vínculo indisoluble, y que:

[...]Los Estados están obligados a respetar y garantizar el pleno y libre ejercicio de los derechos y libertades sin discriminación alguna. El incumplimiento por el Estado, mediante cualquier tratamiento discriminatorio, de la obligación general de respetar y garantizar los derechos humanos, le genera responsabilidad internacional(Corte Interamericana de Derechos Humanos, 2003).

Con fundamento en lo anterior, el derecho internacional de los derechos humanos, prohíbe las prácticas discriminatorias en general, y en mayor grado, se ocupa de prohibir, proteger y sancionar, aquellas conductas discriminatorias contra personas o grupos de personas que pertenezcan a las denominadas categorías sospechosas de discriminación, grupo en el que de conformidad con los conceptos de las Corte Interamericana de Derechos Humanos y la Corte Constitucional colombiana, se encuentran los inmigrantes. Al respecto, es oportuno precisar, que los estados gozan de plena autonomía y soberanía para definir su política migratoria, la cual implica determinar aspectos tales como, qué extranjeros pueden ingresar a su territorio, en qué condiciones y qué requisitos deben cumplirla periodicidad de la permanencia, etc., pero dicha política pública debe tener como referente los estándares internacionales de derechos humanos definidos por los organismos internacionales de derechos humanos, de los cuales Colombia es Estado parte, que tienen como punto de partida y límite, que la política migratoria no se defina atendiendo a prácticas o conductas discriminatorias, y de manera puntual las que constituyan violación del derecho humano a la igualdad.

Con base en lo anterior, se permite que los estados realicen distinciones, más no discriminaciones entre nacionales y extranjeros, por ejemplo, para el caso colombiano, es un criterio de distinción la limitación para ocupar ciertos cargos públicos para los extranjeros o la presentación de cierto tipo de acciones constitucionales como la acción pública de inconstitucionalidad, pero sería discriminación, limitar el ejercicio de las que implican la defensa de sus derechos humanos, tal como ocurre con la acción de tutela. Teniendo en cuenta estos criterios, la Comisión Interamericana de Derechos Humanos señaló en sus opiniones ante la Corte Interamericana de Derechos Humanos que para establecer estos límites y/o distinciones, se requiere analizar o revisar los siguientes criterios:

[...]1) contenido y alcance de la norma que discrimina entre categorías de personas;2) consecuencias que tendrá ese trato discriminatorio en las personas desfavorecidas por la política o prácticas estatales; 3)posibles justificaciones de ese tratamiento diferenciado, especialmente su relación con un interés legítimo del Estado; 4)relación racional entre el interés legítimo y la práctica o políticas discriminatorias; 
y 5) existencia o inexistencia de medios o métodos menos perjudiciales para las personas que permitan obtener los mismos fines legítimos.(...).( La Opinión Consultiva OC-18/03 Condición Jurídica y Derechos de los Migrantes Indocumentados, pag 25, 2003).

Al respecto, concluye la Comisión que tales disposiciones deben ser observadas por los estados, incluso para aquellos que no hubieren ratificado las convenciones sobre derechos humanos, por tratarse de norma que amparan y protegen el derecho a la no discriminación racial, derecho sobre el cual ha existido consenso por parte de la comunidad internacional; es así como, en la Conferencia Mundial Contra el Racismo, la Discriminación Racial, la Xenofobia y las Formas Conexas de Intolerancia, que se celebró en Durban (2001), el eje central fue la eliminación de la discriminación contra los trabajadores migrantes en relación con aspectos como: el salario, la seguridad social, enfermedades laborales, discapacidad, entre otros.

Ahora bien, siguiendo la premisa según la cual los Estados gozan de autonomía y soberanía para regular o reglamentar los derechos humanos, dicha reglamentación no debe hacerse de manera arbitraria y/o caprichosa, sino mediante leyes acordes a la razonabilidad y proporcionalidad en materia de derechos humanos, y respetando el principio rector de estos, como es la dignidad humana, así como los estándares mínimos de protección en relación con el derecho al trabajo, los cuales son, a saber: son derechos irrenunciables, ciertos e imprescriptibles, el derecho a la seguridad social; $y$ finalmente, como lo señala la Comisión de Derechos Humanos, "c) la restricción debe estar "racionalmente relacionada con el objetivo legítimo"; y d) no deben existir "otros medios de conseguir esos fines que sean menos onerosos para los afectados"(Corte Interamericana de Derechos Humanos, 2003)(Cursiva fuera de texto).

Por lo que, estas restricciones, deben hacerse dentro del marco regulatorio dispuesto por la Organización Internacional del Trabajo (OIT) y lo señalado en la Convención Internacional sobre la Protección de los Derechos de Todos los Trabajadores Migratorios y de sus Familiares, los cuales señalan que, en materia laboral no son razonables las discriminaciones, ni aun la que atienden a la situación migratoria. Lo anterior, en aras de evitar la generación mundial de conductas xenofóbicas o nacionalismo peligroso o excluyente.

En este sentido, siguiendo el derrotero internacional de derechos humanos, Colombia en la construcción de la política pública migratoria, o al expedir las distintas regulaciones en la materia y/o las decisiones judiciales que recaigan sobre temas migratorios, debe hacerlo tomando como punto de partida el Derecho Internacional de los Derechos Humanos y el marco internacional en materia laboral, los cuales precisan que una diferencia con base en la situación de extranjería o en el origen nacional es irrazonable, por cuanto no se considera una distinción, sino una discriminación, ya que su sustento ontológico no es por motivos objetivos y razonables, y ello hace que su fin no sea legítimo. En este caso, se debe someter la medida al test de proporcionalidad en su nivel más intenso, en sentido de que supere los estándares internacionales de derechos humanos.

En materia de derechos humanos, los Estados adquieren obligaciones de regulación, protección, garantía y de abstención, no solo respecto de los nacionales, sino de todas las personas residentes en el territorio nacional, por lo que queda inmersa dentro de la obligación de protección y garantía, el compromiso de no tolerar conductas discriminatorias en contra de los inmigrantes por parte de los nacionales, en relación con los primeros, es deber del Estado colombiano no establecer discriminación en materia de derechos humanos, en atención a si están documentados o no; de hacerlo, tales medidas deben ser razonables y proporcionales, es decir, basarse en una distinción y no en una discriminación, en buena hora, esta ha sido la línea demarcada por la Corte Constitucional colombiana cuando se trata de la protección de derechos humanos de la población inmigrante. 


\section{Conclusiones}

El desarrollo del derrotero internacional, permite arribar a las siguientes conclusiones:

A partir de los tratados y convenios internacionales de derechos humanos suscritos por Colombia existe la obligación para el Estado colombiano, de proteger y garantizar los derechos humanos de todas las personas residentes en el territorio nacional, sean nacionales o extranjeros, y en este último caso, dicha protección no puede depender de su situación migratoria.

La política pública migratoria de Colombia debe contener como eje central la garantía del derecho a la igualdad y el principio de no discriminación por razón del origen nacional, ya que por regla general todo tipo de discriminación en consideración al origen nacional, se entenderá como una categoría sospechosa de discriminación.

Al desarrollar la política pública migratoria el Estado colombiano goza de autonomía, pero el límite y sustento axiológico de estalo constituyen el derecho a la igualdad y el principio de no discriminación.

De conformidad con los documentos internacionales de derechos humanos en materia laboral referidos a la población migrante, no puede constituirse en un parámetro regulatorio el tener o no estatus migratorio; en tal sentido, toda medida en materia de derechos laborales que contenga un trato diferenciado en relación con la situación migratoria, será considerada arbitraria e irrazonable, por ende, discriminatoria.

Toda política pública, normas internas y decisiones judiciales en Colombia, en materia migratoria, deben responder a los parámetros internacionales de derechos humanos lo que permite señalar que solo se deben adoptar medidas que permitan alcanzar fines legítimos, y no que promuevan o realicen apología a la xenofobia o generen un nacionalismo peligroso.

Finalmente, señalar que en materia de derechos humanos el Estado colombiano adquirió en el artículo 2 de la Constitución Política el compromiso de proteger a TODOS los habitantes del territorio nacional, sin importar su origen nacional, en su vida, bienes, honra y demás derechos y libertades.

\section{Referencias bibliográficas}

Asamblea Nacional Constituyente de Colombia. (1991). Constitución Política de Colombia, articulo 53. Obtenido de Secretaria del Senado de Colombia: http://www.secretariasenado.gov.co/senado/ basedoc/constitucion_politica_1991_pr001.html\#53.

Comité de Derechos Humanos de las Naciones Unidas. (10 de noviembre de 1989). Observación General 18, Numeral 7. Obtenido de ACNUR: http://www.acnur.org/t3/fileadmin/scripts/doc.php?file=t3/ fileadmin/Documentos/BDL/2001/1404

Corte Constitucional, Sala Plena. (04 de febrero de 2003). Sentencia C-067/03. M. P. Marco Gerando Monroy Cabra. Recuperado de: https://www.corteconstitucional.gov.co/relatoria/2003/c-067-03.htm

Corte Constitucional, Sala Plena. (01 de junio de 2018). Sentencia T-210/18. M. P. Gloria Stella Ortiz Delgado. Recuperado de: https://www.corteconstitucional.gov.co/relatoria/2018/t-210-18.htm

Corte Interamericana de Derechos Humanos. (17 de septiembre de 2003). La Opinión Consultiva OC-18/03 Condición Jurídica y Derechos de los Migrantes Indocumentados, pag 25. Obtenido de ACNUR: http://www.acnur.org/t3/fileadmin/Documentos/BDL/2003/2351.pdf?view=1 
Corte Interamericana de Derechos Humanos. (17 de septiembre de 2003). La Opinión Consultiva OC-18/03 Condición Jurídica y Derechos de los Migrantes Indocumentados, Página 100. Obtenido de ACNUR: http://www.acnur.org/t3/fileadmin/Documentos/BDL/2003/2351.pdf?view=1

Corte Interamericana de Derechos Humanos. (17 de septiembre de 2003). La Opinión Consultiva OC-18/03 Condición Jurídica y Derechos de los Migrantes Indocumentados, Página 96 . Obtenido de ACNUR: http://www.acnur.org/t3/fileadmin/Documentos/BDL/2003/2351.pdf?view=1

Corte Interamericana de Derechos Humanos. (17 de septiembre de 2003). Opinión Consultiva OC-18/03 Condición Jurídica y Derechos de los Migrantes Indocumentados. Obtenido de ACNUR: http:// www.acnur.org/t3/fileadmin/Documentos/BDL/2003/2351.pdf?view=1

Corte Interamericana de Derechos Humanos. (17 de septiembre de 2003). Opinión Consultiva OC-18/03 Condición Jurídica y Derechos de los Migrantes Indocumentados, Página 103, Numeral 84. Obtenido de ACNUR: http://www.acnur.org/t3/fileadmin/Documentos/BDL/2003/2351. pdf?view=1

Corte Interamericana de Derechos Humanos. (17 de septiembre de 2003). Opinión Consultiva OC-18/03 Condición Jurídica y Derechos de los Migrantes Indocumentados, Página 103, numeral 85. Obtenido de ACNUR: http://www.acnur.org/t3/fileadmin/Documentos/BDL/2003/2351. pdf?view $=1$

Corte Interamericana de Derechos Humanos. (17 de septiembre de 2003). Opinión Consultiva OC-18/03 Condición Jurídica y Derechos de los Migrantes Indocumentados, Página 26. Obtenido de ACNUR: http://www.acnur.org/t3/fileadmin/Documentos/BDL/2003/2351.pdf?view=1

Naciones Unidas. (10 de diciembre de 1948). Declaracion de Derechos Humanos, art.2. Obtenido de Naciones Unidas: http://www.un.org/es/universal-declaration-human-rights/

Naciones Unidas. (10 de diciembre de 1948). Declaracion Universal de Derechos Humanos. Obtenido de Naciones Unidas: http://www.un.org/es/universal-declaration-human-rights/

Naciones Unidas. (10 de diciembre de 1948). Declaracion Universal de Derechos Humanos, art.7. Obtenido de Naciones Unidas: http://www.un.org/es/universal-declaration-human-rights/

Naciones Unidas. (16 de diciembre de 1966). Pacto Internacional de Derechos Civiles y Políticos, art.26. Obtenido de Naciones Unidas Derechos Humanos Oficina Alto Comisionado: http://www.ohchr. org/SP/Professionallnterest/Pages/CCPR.aspx

Naciones Unidas. (16 de diciembre de 1966). Pacto Internacional de Derechos Civiles y Políticos, artículo2 numeral1. Obtenido de Naciones Unidas Derechos Humanos Oficina Alto Comisionado: http:// www.ohchr.org/SP/Professionallnterest/Pages/CCPR.aspx

Naciones Unidas. (18 de diciembre de 1990). Convención Internacional sobre la Protección de los Derechos de Todos los Trabajadores Migratorios y de sus Familiares. Obtenido de Naciones Unidas Derechos Humanos Oficina Alto Comisionado: http://www.ohchr.org/SP/Professionallnterest/ Pages/CMW.aspx

Naciones Unidas. (18 de diciembre de 1990). Convención Internacional sobre la Protección de los Derechos de Todos los Trabajadores Migratorios y de sus Familiares, artículo 26. Obtenido de 
Naciones Unidas Derechos Humanos Oficina Alto Comisionado: http://www.ohchr.org/SP/ Professionallnterest/Pages/CMW.aspx

Naciones Unidas. (18 de diciembre de 1990). Convención Internacional sobre la Protección de los Derechos de Todos los Trabajadores Migratorios y de sus Familiares, artículo 25 numeral 1. Obtenido de Naciones Unidas Derechos Humanos Oficina Alto Comisionado: http://www.ohchr. org/SP/Professionallnterest/Pages/CMW.aspx

Naciones Unidas. (18 de diciembre de 1990). Convención Internacional sobre la Protección de los Derechos de Todos los Trabajadores Migratorios y de sus Familiares, artículo 7. Obtenido de Naciones Unidas Derechos Humanos Oficina del Alto Comisionado: http://www.ohchr.org/SP/ Professionallnterest/Pages/CMW.aspx

Naciones Unidas. (10 de diciembre de 1948). Declarcion Universal de Derechos Humanos, preambulo. Obtenido de Naciones Unidas: http://www.un.org/es/universal-declaration-human-rights/

OIT Américas. (2016). La migración laboral en América Latina y el Caribe. Diagnóstico, estrategia y líneas de acción de la OIT en la región. Perú: Organziación Internacional del Trabajo.

Organizacion de Estados Americanos. (noviembre de 1969). Convención Americana Sobre Derechos Humanos. Obtenido de ACNUR: http://www.acnur.org/fileadmin/scripts/doc.php?file=fileadmin/ Documentos/BDL/2001/0001

Organizacion de Estados Americanos. (noviembre de 1969). Convencion Americana Sobre Derechos Humanos, articulo 24. Obtenido de ACNUR: http://www.acnur.org/fileadmin/scripts/doc. php?file=fileadmin/Documentos/BDL/2001/0001

Organización de Estados Americanos. (noviembre de 1969). Convención Americana Sobre Derechos Humanos, numeral 1 artículo1. Obtenido de ACNUR: http://www.acnur.org/fileadmin/scripts/ doc. php?file=fileadmin/Documentos/BDL/2001/0001

Organización de Estados Americanos. (noviembre de 1969). Convencion Americana Sobre Derechos Humanos, preambulo. Obtenido de ACNUR: http://www.acnur.org/fileadmin/scripts/doc. php?file=fileadmin/Documentos/BDL/2001/0001

Organizacion Internacional del Trabajo. (1958). C111 - Convenio Sobre la Discriminación (empleo y ocupación). Obtenido de Organización Internacional del Trabajo: http://www.ilo.org/dyn/normlex/ es/f?p=NORMLEXPUB:12100:0::NO::P12100_ILO_CODE:C111

Organización Internacional del Trabajo. (1958). C111- Convenio Sobre la Discriminación (empleo y ocupación), artículo 1. Obtenido de Organizacion Internacional del Trabajo: http://www.ilo.org/ dyn/normlex/es/f?p=NORMLEXPUB:12100:0::NO::P12100_ILO_CODE:C111

Organización Internacional del Trabajo. (24 de junio de 1975). R151 Recomendación sobre los Trabajadores Migrantes . Obtenido de Organización Internacional del Trabajo: http://www.ilo.org/dyn/normlex/ es/f?p=NORMLEXPUB:12100:0::NO::P12100_INSTRUMENT_ID:312489 